\title{
МЕТОДОЛОГИЧЕСКОЕ ЗНАЧЕНИЕ МАРКСИСТСКОЙ КОНЦЕПИИ ФИКТИВНОГО КАПИТАЛА ДЛЯ АНАЛИЗА СОВРЕМЕННОЙ СТАДИИ РАЗВИТИЯ ГЛОБАЛЬНОГО КАПИТАЛА
}

\author{
(c) 2018 Ермолаев Константин Николаевич
}

доктор экономических наук, профессор

заведующий кафедрой «Институциональной экономики и экономической истории»

Самарский государственный экономический университет

443090, г. Самара, ул. Советской Армии, д. 141

E-mail: ermolaevkn@yandex.ru

В данной статье рассматривается методологическое значение авторской трактовки категории «титульный капитал» для анализа сущности фиктивного капитала и его виртуализации, что является чрезвычайно важным в исследовании новых явлений и тенденций развития финансового рынка постиндустриальной экономики в эпоху глобализации.

Ключевые слова: титульный капитал, капитал-собственность, ожидаемая ценность фиктивный капитал, фиктивная стоимость.

Экономическое наследие К. Маркса в настоящее время все чаще становится объектом изучения представителями различных направлений экономической теории. Отмечаемое в 2018 году 200-лектие со дня его рождения, стало еще одним поводом обратиться к оценке ряда фундаментальных положений марксизма с позиции современности. Одним из них является теория фиктивного капитала, которая до настоящего времени остается весьма дискуссионной, хотя изучение её имеет длительную историю.

Исследуя природу капитала, воплощенного в ценных бумагах, К. Маркс [1] а затем и Р. Гильфердинг [2] использовали категорию «фиктивный капитал». Этот капитал рассматривался буквально как вымышленный (от латинского fictio - вымысел), не имеющий вещественного содержания и собственной стоимости, как специфическая разновидность капитала, не соответствующая канонам трудовой теории стоимости, существенно отличающаяся от реально функционирующего действительного капитала, разрывающая естественную непосредственную связь собственности с производством. Эти представления закрепились в качестве основополагающих в трудах их последователей в советской и современной российской экономической литературе.

Позднее, в 60-80 гг. XX в. в работах советских и российских экономистов [3] были существенно расширены представления о причинах возникновения, существенных признаках, типологии, развитии и субстанциональной основе такого капитала, а также его отличиях от реально функционирующего действительного капитала. Однако принципиальные подходы к пониманию его природы не изменились. Всеми авторами он трактовался как фиктивный, антипод реально функционирующего действительного капитала, не играющий никакой положительной роли в процессе воспроизводства.

Результаты этих исследований наряду с серьезными достижениями продемонстрировали известную ограниченность, связанную как с преувеличением значимости и абсолютизацией трудовой теории стоимости в целом и применительно к объекту исследования, так и с господством изолированного подхода к рассмотрению самой данной категории вне связи с развитием капитала как системного явления. В единстве эти две предпосылки привели к тому, что и большинство современных авторов отождествляют капитал, воплощенный в ценных бумагах и производных финансовых инструментах с фиктивным капиталом, трактуют его как своеобразную экономическую аномалию, как капитал, лишенный вещественного содержания, не имеющий собственной стоимости. (Схематично господствующая точка зрения по проблеме представлена на рисунке 1 ).

В наши дни проблема вновь актуализирована благодаря выходу третьего, исправленного, существенно дополненного и качественно измененного издания монографии А.В. Бузгалина 


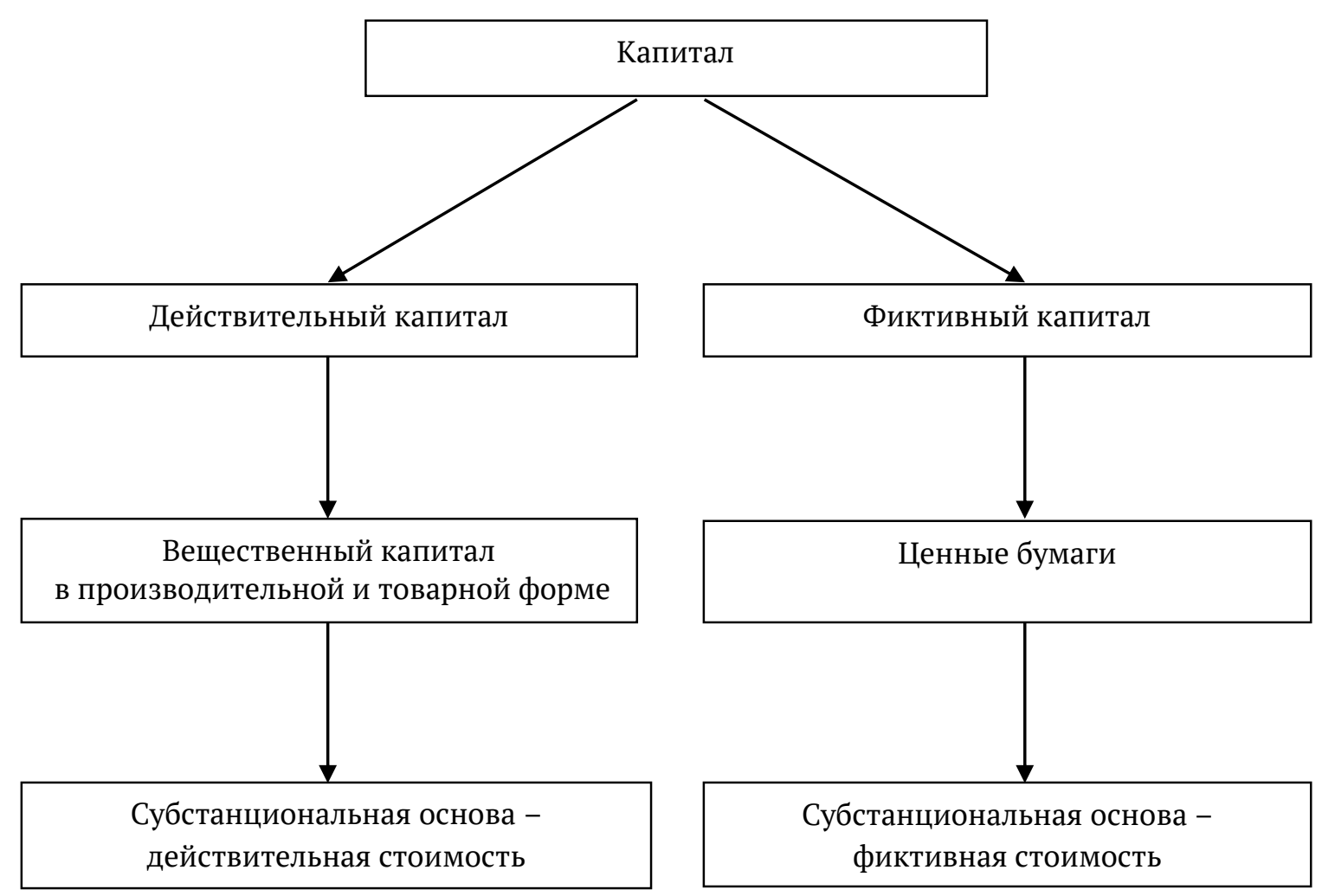

Puc. 1 Сложившиеся научные представления относительно природы фиктивного капитала

и А.И. Колганова «Глобальный капитал» [4], которое является значительным событием в развитии современной экономической теории. Будучи интегральным результатом многолетних исследований авторов, пролегомен «Капитала» XXI века, преследующий цель реактуализации методологии К.Маркса с позиции постсоветской школы критического марксизма на основе диалектики «снятия-развития», посвящен исследованию системных трансформаций производственных отношений капитализма. Актуальность проблемы обусловлена также процессом цифровизации экономики, заставляющим уточнить представления о так называемой «виртуализации» капитала

Одно из центральных мест монографии занимают идеи авторов относительно фиктивности современного глобального капитала и его виртуализации, которые несмотря на логическую стройность и всестороннюю аргументацию, представляются нам далеко не бесспорными. Изложение иной точки зрения по данной проблеме представляется для нас весьма принципиальным потому, что рассмотрение « виртуального фиктивного финансового капитала» для авторов книги имеет концептуальное и фундаментальное значение, отражая едва ли не самый существенный результат современного этапа системной трансформации капиталистических отношений.

А.В.Бузгалин и А.И. Колганов рассматривают фиктивный капитал и как результат трансформации денег из товара-эквивалента в виртуальные деньги, и как глобальный конкретно-всеобщий феномен, выступающий стихийным регулятором движения таких денег, всеобщим регулятором «сетевого» рынка, универсальным «оценщиком» финансовых активов, универсальным механизмом трансакций. Кроме того, авторы характеризуют его как превратную (видимостную) форму, отражающую мнимое содержание, принципиально отличное от действительного, функционирующую в превратном (общественно бесполезном, не создающем материальные и культурные блага) секторе позднего капитализма (сфере многократно мультиплицированных превратных форм), благодаря которым прибыль генерируется в сфере обращения, а также реализуется гегемония глобального корпоративного капитала. Эту сферу авторы оценивают как паразитическую, раковую опухоль на теле стареющего капитализма.

Авторы монографии полагают, что это видимостное, превратное «перевернутое» содер- 
жание данного явления неслучайно и адекватно отражает внешние, видимостные, маскирующие сущность механизмы функционирования рынка. Эти механизмы отражают отрыв движения денежного капитала от движения действительного (производительного) капитала, выражающийся в угнетении «правомерных», «естественных» функций денежного капитала (т.е. тех, что обусловлены его генезисом как средства обслуживания движения производительного капитала, его бытием-для-иного) и росте его «самодавлеющих» функций (для-себя-бытия), основанных на использовании спекулятивных эффектов.

Генезис виртуального фиктивного финансового капитала, по мнению авторов, отражает самоподрыв системообразующих производственных отношений капитализма на базе их прогресса, подрыв капиталистического производства, поскольку, будучи оторванным от материального производства по своей природе, такой капитал приобрел способность многократно увеличивать свои объемы и власть за счет неких виртуальных процессов в финансовой сфере, производства самого себя (денег) из самого себя (денег). Будучи продуктом развития глобализации, тотальных сетей и информационных технологий он стал частью виртуальной реальности, воплощенной в электронных носителях, способных выражать сколь угодно большие денежные суммы в сколь угодно малом носителе, перемещать их с практически мгновенной скорости, хранить сколь угодно долгое время без каких либо издержек, осуществлять трансакции в дватри триллиона долларов в день. Это электронная форма существования сопровождается неопределенностью, нестабильностью, вероятностным и неустойчивым бытием.

А.В.Бузгалин и А.И. Колганов рассматривают возникновение виртуального капитала и обслуживающих его виртуальных денег как новейший этап эволюции форм существования капитала превращение фиктивного капитала в виртуальный капитал, т.е. капитал, стоимостная оценка которого неопределенна, место нахождения которого из-за частоты и многоступенчатости сделок также неопределенно, и собственник которого, по той же причине расплывчат и неуловим.

Данные авторы характеризуют такой капитал как основу фиктивного (симулятивного) рынка, все атрибуты которого все более отрываются от своей основы (частного труда обосо- бленных производителей) и живут за счет самопродуцирования социально-экономической формы, где рыночные формы создаются другими рыночными формами и так далее, безотносительно к их стоимостной, трудовой основе.

В качестве результата А.В.Бузгалин и А.И. Колганов делают фундаментальный вывод [5], согласно которому виртуальная форма этого капитала оказывает, как было отмечено выше, значительное влияние на его содержание:

1. Капитал становится принципиально более мобилен во времени и пространстве, нежели капитал, имеющий другую форму, а скорость оборота капитала имеет принципиальное значение. Виртуальное бытие капитала качественно увеличивает эту скорость, позволяет ему перемещаться в любые точки пространства с практически мгновенной скоростью и с минимальными «транспортными» издержками. Тем самым виртуальный капитал обретает такой носитель, такое материальное воплощение, которые сами по себе являются всемирными и вечными: информация устаревает лишь морально.

2. Виртуальный капитал-деньги оказывается связан с конкретным субъектом, с конкретным положением в социальном пространстве-времени лишь по форме собственности и может менять своего хозяина сколь угодно быстро и часто. Тем самым виртуальный капитал - это капитал, не только оторвавшийся от производства, но и не находящийся сколько-нибудь устойчиво в частной собственности каких либо лиц. Он не является объектом сколько-нибудь устойчивого регулирования и контроля со стороны какого-либо лица.

3. Противоречие между свойствами информации и свойствами капитала, его отчуждение и присвоение становятся феноменами, зависимыми прежде всего от формальных и тоже «виртуальных» правил, регулирующих его движение. Всякие материально-производственные и личностные связи постепенно исчезают и заменяются процессами, протекающими в компьютерных сетях. Те капитал становится зависимым от качества институтов, обеспечивающих поддержание и развитие капиталистической формы информационной сети в целом.

Виртуальный характер фиктивного капитала, по мнению авторов, означает и существенные изменения в социально-экономическом содержании капитала. Этот носитель позволяет в принципе позволяет любому капиталу стать 
всемирным, вечным и предельно подвижным. Имеющий такой носитель капитал лишь формально связан с конкретным собственником, и эти связи постоянно меняются, что является его атрибутивной характеристикой; он зависим во всех своих звеньях от единой информационной системы человечества и является предельно могущественным и предельно уязвимым (от хакеров, владельцев компьютерно-коммуникационных сетей).

Мы полагаем, что рассматриваемая точка зрения не является бесспорной потому, что имманентными системными сущностными свойствами фиктивного капитала называются виртуальность, симулятивность, превратность, свидетельствующие о самоподрыве атрибутивных свойств капитала как такового. Истоки данной позиции заключатся в воспроизведении на качественно новом уровне рассмотренной выше (рисунок 1) позиции сторонников трудовой теории стоимости, что невольно приводит к представлениям о фиктивном капитале как о виртуальном капитале, олицетворяющей процесс «самоподрыва» и «самоотрицания» капиталом самого себя.

Мы полностью согласны с данными авторами в том, что современный глобальный капитал обладает рядом новых черт, по сравнению с эпохой раннего капитализма. Очевидной является финансовая доминанта, выражающаяся в глобальной гегемонии финансового капитала над остальной экономикой и опережающем росте финансового сектора по сравнению с реальным. Налицо определяющее влияние этого сектора на всю систему аллокации ресурсов, направление потоков инвестиций. Не вызывает сомнений, что приоритетное развитие финансового капитала вызвало волну дерегулирования, финансовые спекуляции стали своеобразным «регулятором», субститутом государственного воздействия на экономику. Современный капитал не имеет локализации в пространстве и во времени, постоянно «странствует» по глобальному финансовому рынку, легко уходит из-под любого национального и международного контроля и регулирования. Такой капитал потенциально неустойчив, генерирует финансовую нестабильность, непредсказуемо зависит от действия случайных факторов.

Однако из выше перечисленных процессов А.В.Бузгалин и А.И. Колганов делают выводы, с которыми сложно согласиться. Изменения в характере функционирования современного капитала, данные авторы объясняют его виртуализацией, перемещением в компьютерное киберпространство, сферу транзакций, утратой связи со своей материальной основой и материальным носителем. По их мнению, современный финансовый капитал живет в компьютерных сетях и поэтому он движется постоянно и с очень высокой скоростью, ему свойственны постоянная смена субъекта собственности и размытость, диффузия прав собственности, чрезвычайно высокая мобильность во времени и пространстве, высочайшая концентрация при минимальной интеграции с производственным сектором. Авторы уверены, что виртуальный капитал рубежа XX-XXI вв. становится системой «пузырей» виртуального финансового капитала, которые пусты по своей сущности, но при этом, поглощают огромные и наиболее высококачественные ресурсы. Генезис информационного общества, создает для этого сектора адекватную материальную базу и интенсифицирует его прогресс.

Автор статьи придерживается иной точки зрения. Постоянно возникающее противоречие между стремлением к ничем не ограниченному движению и материально-вещественной ограниченностью конкретных форм воплощения приводит на известном этапе к отмеченному К. Марксом специфическому диалектическому раздвоению капитала на капитал-собственность и капитал-функцию. Капитал-функция, или реально функционирующий, находящийся в товарной, производительной и денежной формах, функционирует в конкретной сфере экономики, реализуя свою репродуктивную и созидательную природу, непосредственно генерирует процесс самовозрастание стоимости. Капитал-собственность, представляющий собой обособленно обращающийся на финансовом рынке титул собственности на истинный капитал, существует в виде ценных бумаг, деривативов и структурных финансовых продуктов. Его предназначение - быть представителем истинного капитала на финансовом рынке и опосредовать перераспределение стоимости, собственности, риска и информации. Эта особая бестелесная невещественная титульная форма существования капитала, опосредующая движение товара-капитал на финансовом рынке.

Благодаря возникновению и самостоятельному движению особого, «титульного» компонента, капитал как таковой, сохраняя свои атри- 
бутивные свойства, переходит в принципиально новое состояние, демонстрируя целый ряд новых особенностей проявления своих сущностных свойств, о которых мы упомянули выше. Однако процесс виртуализации затрагивает не весь капитал как таковой, взятый в целом, а лишь его титульный компонент. При этом он остается неразрывно связанным с капиталом-функцией потоками фундаментальной экономической информации, узами пучков правомочий отражающих фиксацию и изменение принадлежности капитала конкретным субъектам, механизмами хеджирования рисков, процедурами первичного и вторичного рынка капитала. Виртуальным стало лишь титульное движение капитала на финансовом рынке, реальное функционирование капитала осталось материально-вещественным. Диалектически противоречивое единство и взаимосвязь капитала-собственности и капитала-функции не исчезли, а приобрели новую виртуальную форму фиксации. Реально функционирующий, капитал не дематериализуется и не виртуализируется даже в эпоху высоких технологий, компьютеризации и цифровизации. В сети обращаются лишь титулы капитала.

Уважаемые авторы не только абсолютизируют виртуализацию современного капитала, но и рассматривают ее не иначе как проявление самоподрыва и самоотрицания капитала как производственного отношения. Мы категорически против такого понимания процессов, происходящих с современным капиталом.

Возникновение титульного капитала в результате диалектического разъединения капитала-собственности и капитала-функции действительно предполагает отрицание титулом материально-вещественных свойств истинного капитала, его распредмечивание. Но это отрицание диалектическое, сопровождающееся с сохранением «в снятом виде» сущностного единства и внутренней взаимосвязи между титульным и истинным капиталом как двумя диалектически-противоречивыми сторонами единой сущности - капитала как такового. Это не подрыв капитала как явления - это воспроизведение в качественно новом виде коренной сущности капитала, раскрывающей новые его грани.

Таким образом, мы рассматриваем виртуализацию как особую стадию развития титульного компонента капитала, а виртуальный капитал - как одну из форм существования титульного капитала.
Таким образом, автор убежден, что известная виртуализация означает не исчезновение и самоподрыв капитала, как это пытаются представить уважаемые вышеупомянутые авторы, а переход его в новое качество, в котором при сохранении его материальной основы и физической сущности одновременно возникают условия для принципиально новых технологических возможностей движения титульного капитала. Одновременно необходимо подчеркнуть, что те новые свойства и особенности современного капитала, которые подробно исследованы А.В. Бузгалиным и А.И. Колгановым, имеют большую научную ценность, поскольку позволяют с одной стороны, точно охарактеризовать состояние современного глобального капитала, а с другой, более глубоко раскрыть природу титульного капитала и его адекватность проблемам и вызовам эпохи информационной финансовой постиндустриальной экономики на этапе глобализации.

Поэтому автор статьи полагает, что позиция оппонируемой точки зрения, вместе с лежащей в ее основе концепция фиктивного капитала, отраженная на рисунке 1 не является, тупиковой, непродуктивной или полностью ошибочной. Мы полагаем, что она имеет несомненную самостоятельную научную ценность. И вся проблема заключается в том, что она развивалась, по нашему глубокому убеждению, применительно не к тому объекту. Практически все положения данной концепции, по нашему мнению, успешно применимы не к капиталу, воплощенному в титулах собственности, а к другому экономическому явлению - монополизированному рентопродуцирующему ресурсу, генерирующему рентные доходы и являющемуся фиктивным капиталом диаметрально противоположным действительному капиталу реального сектора экономики, на что недвусмысленно указывали Ж. Сисмонди и В. Зомбарт. К глубокому сожалению рентные аспекты теории фиктивного капитала длительное время вообще не брались во внимание практически всеми авторами, и лишь в работах А.В. Мещерова [6], и выполненных под их руководством диссертациях, они стали исследоваться и развиваться с использованием категорий рента и ложная социальная стоимость. (Схематично позиция, защищаемая автором, представлена на рисунке 2).

Такое понимание природы фиктивного капитала и сущности процесса виртуализации, не умаляя методологической и теоретической 


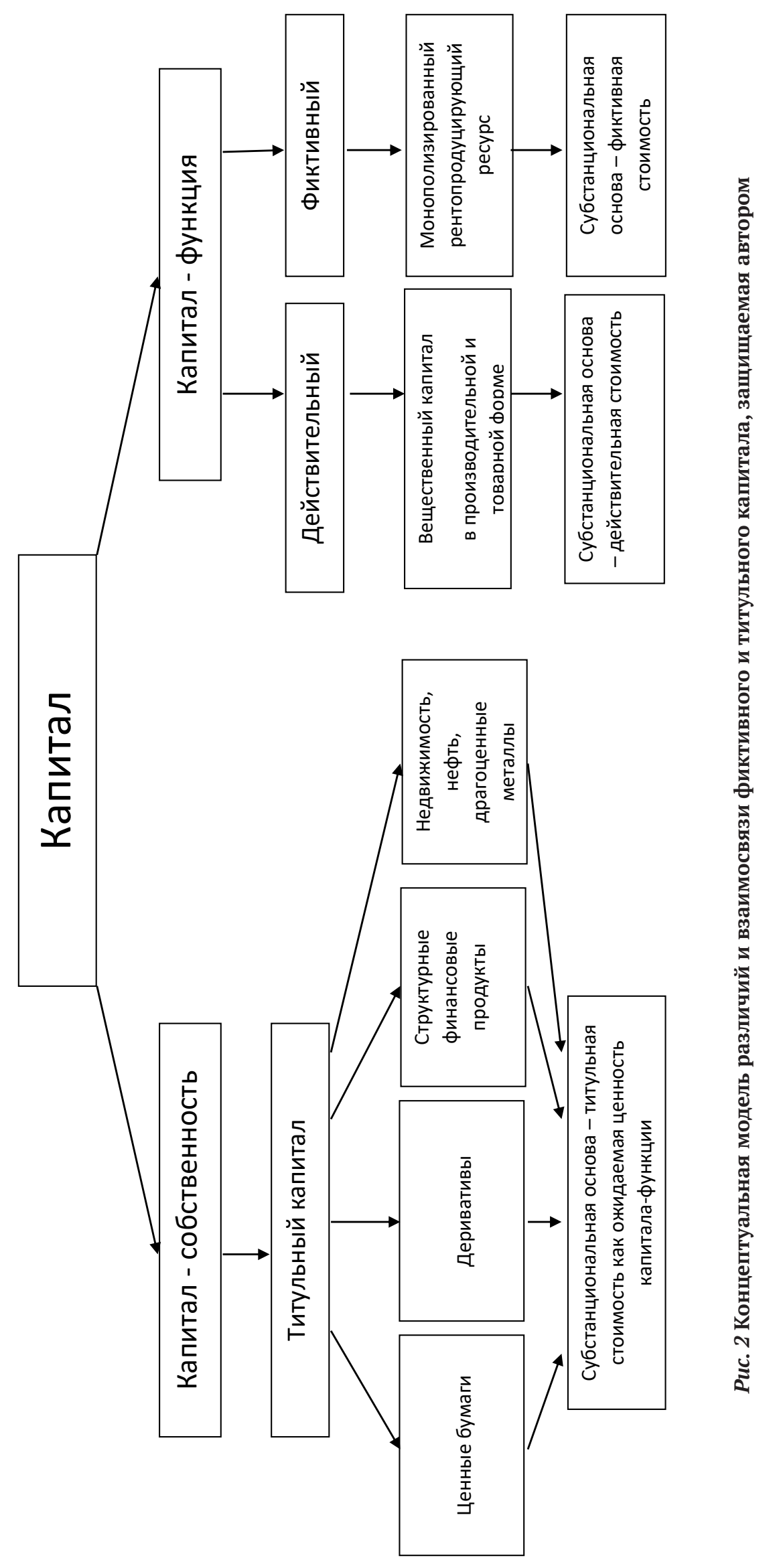


значимости концепции «виртуального фиктивного финансового капитала» А.В.Бузгалина и А.И. Колганова, требует внесения существенных уточнений в характеристику этого феномена нынешнего этапа системных трансформаций глобального капитала.

\section{Библиографический список}

1. Маркс К., Энгельс Ф. Соч.,2-е изд., Т. 25 Ч. 2 с. 18-80

2. Гильфердинг Р. Финансовый капитал. Исследование новейшей фазы в развитии капитализма.М.: Соцэкгиз, 1959. 490 с.

3. Аникин А.В. Кредитная система современного капитализма (исследование на материалах США).М. Наука,1964. С. 28; Брегель Э.Я. Денежное обращение и кредит капиталистических стран.М.: Финансы,1973. 355с.; Коган А.М. Методология исследования кредита в «Капитале» К. Маркса // Вестн. Моск. ун-та, Сер. 7., Экономика,1967.№ 4. С. 31; Краткий курс политической экономии: учеб. пособие. В 2 т. Т. 1/ под ред.Н.А. Цаголова.3-е изд., перераб. и доп. М.: Экономика,1973. 831с.; Леонов С. Фиктивный капитал: содержание и виды.//Экон. Науки. 1980.№ 9 С. 28-33; Мусатов В. Т. Некоторые вопросы анализа категории «фиктивный капитал»// Вестн. Моск. Ун-та,1976.№ 5.С.25-56; Розенберг Д.И. Комментарии к «Капиталу» К.маркса.М.: Экономика,1983. 720 с.; Трахтенберг И.А.денежное обращение и кредит при капитализме. М.: Изд-во АН СССР,1962.C.438-439

4. Бузгалин А.В., Колганов А.И. Глобальный капитал. В2-х т. Т. 2 Теория: Глобальная гегемония капитала и ее пределы («Капитал» re-loaded).-Изд.3-е, испр. и сущ. доп.-М.: ЛЕНАНД,2015-912 С.

5. Бузгалин А.В., Колганов А.И. Глобальный капитал. В2-х т. Т. 2 Теория: Глобальная гегемония капитала и ее пределы («Капитал» re-loaded).-Изд.3-е, испр. и сущ. доп.-М.: ЛЕНАНД,2015 -С 269.

6. Мещеров А.В. Действительная и фиктивная стоимость: ретроспективы и современность [Текст]// А.В. Мещеров .-Экономические науки.- № 1, 2016г, С. 7-13.; Мещеров А.В. Современная экономика и общий закон стоимости [Текст]// А.В. Мещеров .-Экономические науки.- № 2, 2016г, С. 7-14

Поступила в редакцию 04.08.2018 